\title{
STREBLO: THE APP PROTOTYPE FOR MANAGING STRESS IN THE CONSTRUCTION INDUSTRY
}

\author{
Silvia Riva1, Paul Hampton and Ezekiel Chinyio \\ Faculty of Science and Engineering, University of Wolverhampton, Wulfruna Street, Wolverhampton WV1 1LY, \\ $U K$
}

\begin{abstract}
High levels of stress at work, great responsibilities, hazards and lack of balance between tasks and deadlines are common in the daily lives of many construction workers. Changing the patterns of thinking and behaviours is not an easy mission, and it requires constant support, learning and determination. E-health applications can contribute to this change through their ability to foster continuous interaction with the user. Mobile phone apps have shown promising results in the field of 'e-health and wellbeing'. Accordingly, an App is being designed as a self-help system for stress management which will enable construction workers to 1) detect the onset of stress quite early, 2) track their stress status, 3) empower persons to cope with stressful and/or demanding situations in an adaptive way, 4) improve and streamline the operability of job tasks, and 5) optimise efficient solutions for the construction industry. The development of this innovative app, known as Streblo, is part of a wider research that is studying stress management in the construction industry. Streblo's blueprint will match personality traits with coping strategies in real-life situations. Its inputs are being generated from a field study that has commenced, where 23 structured interviews have been used to collect data from construction workers on their 1) personality and 2) behaviours while experiencing stress. Results of the data collection and analysis are being used to develop Streblo (an App) with IT experts. The paper reports the detail development and performance of Streblo's prototype. Ultimately, users will be able to engage Streblo on electronic devices (mobile phones, tablets, and computers) through both text and image-based communication obtain real-time solutions and feedbacks on their stress status. Streblo will enhance and support attitude and behavioural changes in people who suffer from stress symptoms in the construction industry.
\end{abstract}

Keywords: Stress, Tool, Coping, App design, Streblo, Well-being

\section{INTRODUCTION}

The UK Health and Safety Executive (HSE) has defined work related stress as the adverse reaction people have to excessive pressure or other types of demand placed on them. Due to the risky and often problematic environments of construction projects, time management and other crisis-ridden working issues, the construction industry has long been known to be stressful (Bowen et al., 2014; Chan et al., 2018). Stress arises when there is an incongruity between a worker's estimated capability and resources and actual context to cope with his or her activity (Leung, Liang and Yu, 2016; Haydam and Smallwood, 2016). Stress in the construction industry has been tightly linked to arduous activities, scarce support of relationships, difficult climates, uncomfortable physical environments, work overload, lack of autonomy and conflicting roles. Stress can impact negatively on an individual's psychological health and performance, and can manifest as

${ }^{1}$ s.riva@wlv.ac.uk

This paper was presented as a working paper (not published conference paper) at the ARCOM 2018 Conference, Belfast, UK, 3-5 September 2018. This content can be represented for a Conference paper.

Permission was obtained by the ARCOM Steering Committee as the paper was not published as an indexed paper. Google and other source cannot index working papers as individual papers. 
a simple strain or sense of frustration, low motivation and lesser productivity (Lingard and Francis 2004; Love et al., 2010; Chan et al., 2012; Bowen et al., 2014).

In 2006, a pioneering large study conducted by the Chartered Institute of Building (CIOB) in the UK, showed how stress in the construction industry was extremely linked to inter alia, interpersonal and cultural/organisational factors i.e. lack of feedback (56.8\%), poor communication $(55.7 \%)$, inadequate staffing $(55 \%)$, too much work $(64.1 \%)$, ambitious deadlines (59.7\%), pressure (59.9\%) and conflicting demands $(52.2 \%)$. On the contrary, site safety, inadequate equipment and poor physical environment were among the lowest scoring factors with over $80 \%$ of the survey respondents stating that these were not a cause of occupational stress (Campbell, 2006).

Stress impacts not only on individuals' physical and emotional status, but also on their job and general performance in terms of efficiency, outputs, teamwork and collaboration (Leung, Chan and Cooper, 2014; Enshassi et al., 2018). Stress in Construction has been associated with a high presence of anxiety and depression, whereby workers spend less time maintaining their health status, take on less personal responsibility, and invest less energy in their work activities (Smallwood and Ehrlich, 1997; Derr et al., 2001; Haynes and Love, 2004; Love, Edwards and Irani, 2010; Enshassi et al., 2018). It is therefore important for players to cope with a challenging construction industry and be able to deal with stress (Bowen, Govender and Edwards, 2014; Chan, Leung, and Yuan, 2014). 'Coping' is the psychological description of the ability to deal with stress and it represents the behavioural and cognitive solutions an individual adopts to manage stress (Lazarus, 1966). Coping behaviours may be adaptive (when they help people to find efficient solutions to their stress) or maladaptive (when they cause detrimental effects at the physical and/or emotional levels).

\section{E-Self Management Applications}

E-self management applications may represent a valid support to managing stress and they can easily be adapted within the work environment (Wu et al., 2017). An App may contribute to help the worker to manage his/her activities autonomously and prevent any detrimental outcomes. Eself management applications can contribute to monitoring the level of stress and users' health status through their ability to foster continuous interaction. Particularly, mobile phone apps have shown promising results in the field of 'self-management, health conditions and wellbeing' (Payne et al., 2015; Whitehead, and Seaton, 2016) with good results in terms of improved quality of life, reduced need for care and cost efficiency. Different applications have shown significant improvement in health distress and increased self-efficacy and satisfaction (Lorig et al., 2001, Bauer et al., 2014). Support for different health conditions is now feasible through information and communication technology (ICT) e.g. self-management of appointments and check-up visits to doctors, smartwatches, and virtual trainings, social networks and discussion forum. There are also apps that can link vital symptoms with personal health devices and electronic medical record systems (Wang et al., 2014; Årsand et al., 2015). Apps can be implemented in work settings to transmit the unique needs of workers with a mental health condition. Individuals can choose different functionalities of apps toward managing their particular problems and grade of severity. Many apps permit personalization to a specific user's needs and goals (Shaw et al., 2014; Jonkman et al., 2016).

The potential usefulness of apps may be superior for some specific mental health conditions, such as stress. Mobile applications for stress management have been applied in different sectors (e.g. health) with promising results (e.g. Gaggioli et al., 2014; Engel et al., 2015; Khusid and Vythilingam, 2016). However, no construction-specific application exists. Hence, the aim of this paper, based on an underpinning research, is to attempt to describe the design of an interactive 
App for construction professionals for coping with stressful events at the workplace. The overall goal of this tool is to detect:

1. Early signs of stress; that is the mental and physical state resulting when the resources of the individual are inadequate to cope with the demands and pressures of the situation.

2. Stress consequences that can undermine the achievement of goals, both for individuals and for organisations; monitor these; and propose innovative solutions to overcome problems for construction workers.

3. Signs of stress that can be seen in people's behaviours. Responses to stress may be in the areas of feelings (e.g. anxiety, depression, irritability, fatigue), behaviour (e.g. being withdrawn, aggressive, tearful, unmotivated), thinking (e.g. difficulties in concentration and problem solving) or physical symptoms (e.g. palpitations, nausea, headaches).

\section{METHODS}

The development of the Streblo app (prototype) included participatory design (interviews) with inputs from different construction workers $(\mathrm{N}=20)$ and IT academic staff $(\mathrm{N}=3)$. The interviewees consisted of 5 operational managers and 15 supervisors while the academic staff consulted were two informatics engineers and one specialist in the Build Environment.

Brief structured Interviews facilitated the assessment of users' needs and afforded potential consumer input into the app's focus and features. Table 1 describes the content of these brief interviews.

\section{Table 1: Interview guide}

\begin{tabular}{l}
$\begin{array}{l}\text { Construction workers' } \\
\text { questions }\end{array}$ \\
\hline $\begin{array}{l}\text { Open question: Which are the main features that a technological tool should have to help persons to } \\
\text { cope with stress? }\end{array}$ \\
\hline Which are the technological requirements for a good app? \\
\hline Which services an app should provide? \\
\hline How to incorporate graphical aspects?
\end{tabular}

The interview is part of a larger study about stress management in the construction industry characterised by the collection of both quantitative and qualitative data. The results described below are inspired from the results of the interviews and form the large qualitative study based on an ethnography research at 3 Construction sites: this lasted 6 months and involved more than 50 observed participants at work.

A Dephi approach (Delphilike) was applied in which a forecasting method based on the results of questions is sent to a panel of experts (Benarie, 1988; Nevo and Chan, 2007). The responses generated during the interviews were transcribed and summarised, manually. 


\title{
RESULTS
}

The suggestions generated from the analysis led directly to the development of Streblo's features and content. For example, some research participants requested tools that they could use easily at the workplace (e.g. for remembering previously inserted or stored user-data). Some participants also wanted the app to provide a record of the suggestions received. Employing this user-centric design procedure was intended to develop an app that would be most relevant to the users' needs and provide functionalities that were most attractive to them. Streblo is being designed to be used either as a stand-alone psychological and self-management tool or to cope efficiently with stress at the Construction workplace. Results of the preliminary data collection have permitted the delineation of the main features of the Streblo app (Table 2).

\section{Table 2. Features of Streblo}

\author{
Main features \\ Graphical-friendly (the tool must be graphically easy to learn and use); \\ Fully integrated in their usual smartphone \\ Customizable (lay people with no programming skills should be able to use all the functionalities); \\ Discreet (the application should not interfere with normal mobile phone usage or with normal \\ working routine activities). \\ Multilevel usability (the application is connected to an icloud system permitting the user to use the \\ App on smartphone, IPad or PC according to personal requirements and/or laws, e.g. a user working \\ on site may use the application on his/her PC because the law does not permit the use of smartphone \\ during routine activities).
}

\section{The Streblo App}

\section{Design Principles}

The following design inputs and principles generated through the research were applied in developing the prototype web-based stress management system:

Social connections. New information and knowledge are shared when different workers are invited to online conversations. Also, people with previous situation of stress, who have managed to recover from difficult situations in construction job activities, can contribute with their insights. By this, both strong-tie and weak-tie relationships are made possible.

a. Self-Learning on Stress. Through questions and practical experiences, users can get help in their learning processes and become more aware and more confident to cope with them.

b. Wide range of solutions. The system should help the users to enhance their strategies in order to cope with stress better and positively. This can be through an array of behaviours, such as advice on how to approach a specific stressful situation, and how to interpret a particular event and demanding requests.

c. Constant e-Learning. Continuous efforts are needed for people who want to change maladaptive coping behaviours and patterns of actions. Therefore, it is important that the system has tools for ongoing help in everyday events at the workplace.

d. Practical A. The inner architecture of the system is learning based on the users and their experiences. By identifying good solutions and adaptive behaviours, feedback on what goes on in the users' lives is available, and the system can be adjusted when necessary. For example, exercises can be tailored to better fit the needs of the user for 
a circumstance.

e. Multimedia Tutorial. E-learning between the user and the system is mediated by using a tutorial. Breathing exercises can, for example, be easily demonstrated through online video clips. Likewise, other exercises can be recommended to mitigate stress.

\section{Web System Components}

The app consists of four major sections:

1. Who are you? This section provides psychological information about personality (e.g. symptoms, prevalence rates, how stress develops) and various types of behaviours that are available. It includes information about habitual behaviours, cognition and emotional patterns.

2. Self-Assessment: This section includes the Streblo COPE Inventory version (a wellvalidated, widely used self-report that measures the ways to cope with stress. After completing the COPE, users are provided with interpretive feedback about the efficacy of their coping strategies (adaptive, maladaptive strategies or alerting information). Users can also track their strategies over time by viewing a line graph of past assessments. Finally, users can schedule future assessments at regular intervals (e.g. monthly).

3. Manage stress: This section provides solutions to help address stress symptoms and manage difficulties at the workplace. When a coping behaviour is selected, the user is invited to check if the coping solution adopted is adaptive or not. If not, the system offers solutions to the user. Depending on the problem selected, the user is offered a psychological-based coping tool (e.g. paced breathing, progressive muscle relaxation, concentration exercises, engage in pleasant events) or an organisational-based coping tool (e.g. divide your task into subtasks, identify priorities). If users do not like a solution presented to them, they can choose another option. Table 3 illustrates an example of adaptive, maladaptive coping behaviour and associated solutions.

4. Find Support: This section allows users to easily reach out to sources of support when needed, including their GP, NHS mental support and other allied organisations that offer help for managing stress. Streblo also provides users with a variety of links and phone numbers to facilitate finding face-to-face interaction with qualified professionals.

\section{DISCUSSION AND CONCLUSION}

There is a considerable body of existing research regarding mobile interventions for selfmanagement; however new research is also required to test the effectiveness of these new instruments in the field, such as in the case of the construction industry. Meanwhile, new studies are also required to evaluate how such applications can determine a positive change over the time in managing a health condition in different settings, such as stress at work. In this context, Streblo represents a prominent and innovative solution for stress management with potential important impact on personal wellbeing and quality of life.

While previous research in construction management has mainly focused on the effect of stress and its influence on the performance of an individual and project outcomes, very few studies have touched on the stress experience (Sutherland and Davidson, 1993, Leung et al., 2008). 
Table 3: Coping behaviours and solutions in Streblo model

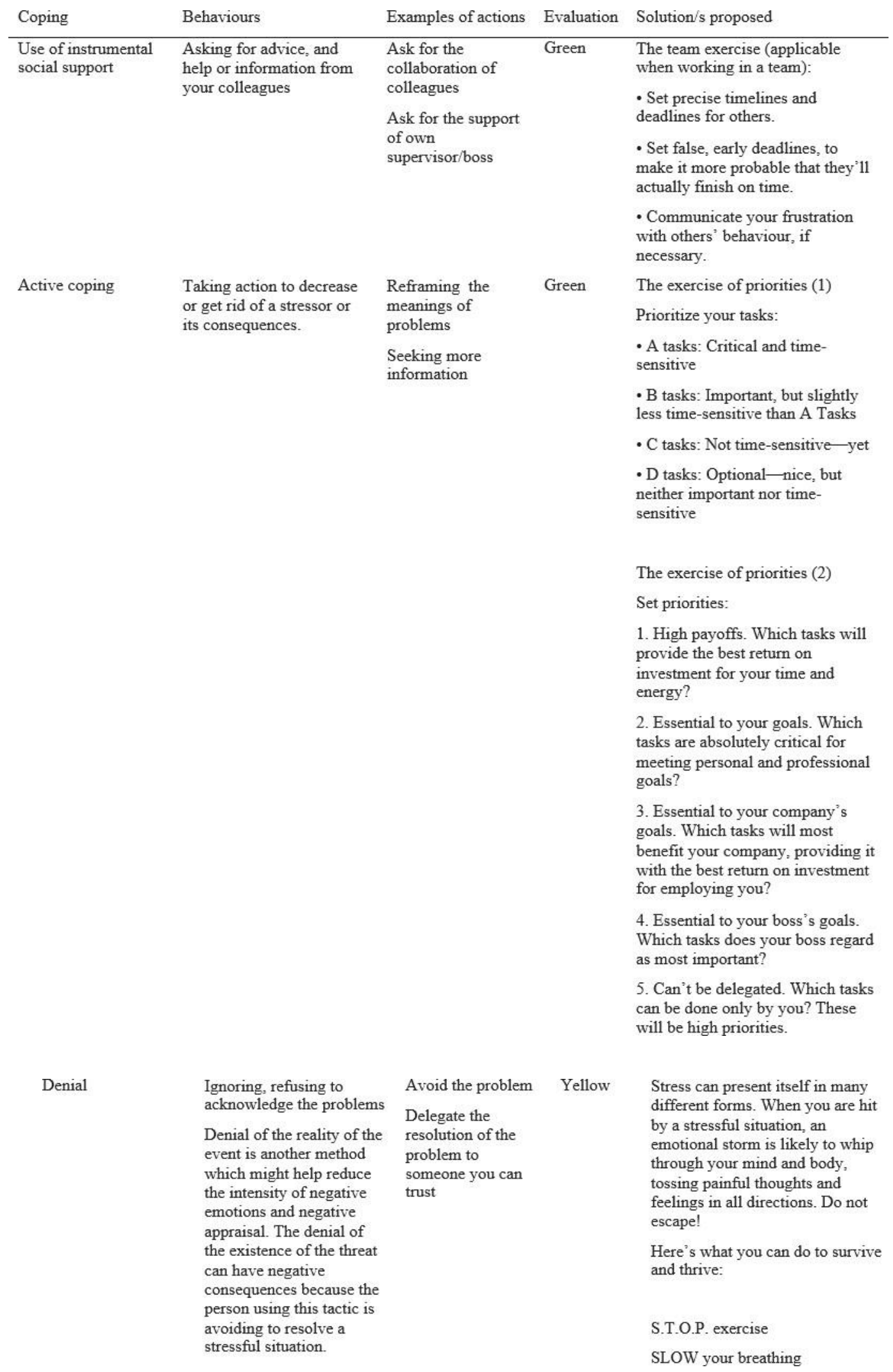




\begin{tabular}{|c|c|c|c|}
\hline Coping & Behaviours & Examples of actions Evaluation & Solution/s proposed \\
\hline & & & $\begin{array}{l}\text { - Take a few deep breaths, and } \\
\text { mindfully observe the breath } \\
\text { flowing in and out. This will help } \\
\text { to anchor you in the present. }\end{array}$ \\
\hline & & & TAKE note \\
\hline & & & $\begin{array}{l}\text { - Take note of your experience at } \\
\text { this moment. Notice what you are } \\
\text { thinking. Notice what you are } \\
\text { feeling. }\end{array}$ \\
\hline & & & $\begin{array}{l}\text { Notice what you are doing. Notice } \\
\text { how your thoughts and feelings are } \\
\text { swirling around, and can easily } \\
\text { carry you away if you allow them. }\end{array}$ \\
\hline & & & OPEN up \\
\hline & & & $\begin{array}{l}\text { - Open up around your feelings. } \\
\text { Breathe into them and make room } \\
\text { for them. }\end{array}$ \\
\hline & & & $\begin{array}{l}\text { Open up to your thoughts too: take } \\
\text { a step back and give them some } \\
\text { room to move, without holding } \\
\text { onto them or trying to push them } \\
\text { away. See them for what they are } \\
\text { and give them space, rather than } \\
\text { fusing with them. }\end{array}$ \\
\hline & & & PURSUE your values \\
\hline & & & $\begin{array}{l}\text { - Once you've done the above } \\
\text { three steps, you will be in a mental } \\
\text { state of mindfulness. The next step } \\
\text { is to respond to the crisis by } \\
\text { pursuing a valued course of action. } \\
\text { Connect with your values: ask } \\
\text { yourself, }\end{array}$ \\
\hline & & & $\begin{array}{l}\text { 'What do I want to be about, in the } \\
\text { face of this crisis? What do I want } \\
\text { to stand for? How would I like to } \\
\text { act, so that I can look back years } \\
\text { from now and feel proud of my } \\
\text { response?' }\end{array}$ \\
\hline
\end{tabular}

(NB: Adapted from Mancini, 2003)

The emergence of mobile self-management and wellbeing solutions heralds a new era in personal management, and it is particularly pioneering in the field of construction management. The research described in this paper aimed to assess a prototype innovative app for the management of the common stressors faced in construction projects. Streblo has been developed using a robust, bottom-up, qualitative approach that included consultation with as many stakeholders as appeared to be necessary. The first prototype of the app is based on documented knowledge to provide a firm foundation for subsequent refinement which will require inputs from expert stakeholders on fitness-for- purpose. At its future operational level, Streblo will be tested among different construction workers to measure acceptability and efficacy prior to its public diffusion.

\section{CONCLUSIONS AND RECOMMENDATION}

The negative effects of stress at work in terms of emotional disorders and organisational difficulties have urged the need for new tools and solutions, especially direct-to-user tools such as mobile applications. The use of Streblo should orientate the better management of health and safety issues in Construction.

An important aspect of Streblo is that a user does not just make an assessment to see if they have a problem with stress in the workplace, but the app also helps them to eliminate or at least 
ameliorate the potential impacts of any identified stressor. The potential of Streblo is thus wide and in line with the actual and current needs of professionals working in the construction industry. The study underpinning Streblo is investigating how technology has been used to influence adaptive coping behaviours and synthesize key aspects into a conceptual model for creating a new mobile application. The conceptual model provides further knowledge of key aspects to consider when developing persuasive tools that aim to encourage more efficient ways of coping with stressful events in construction.

So far, published mobile phone applications have shown promising results. In this paper, we have presented a new prototype of a mobile phone app for stress management associated with a web-based system. This preliminary work will be followed-up by user- based evaluations to identify the needs to be addressed in the next iteration of the design. The research reported in this paper constitutes a significant step towards the understanding and management of potentially stressful situations and their influence on the efficiency and effectiveness of construction industry participants. Similarly, there are triple bottom line implications for all concerned. In particular, those most likely to be exposed to high stressors may expect to at least receive some serious consideration from their managers and advice for self-help. New data as well as new hypothesis on coping modalities, consequences and wellness at work are expected from this study. These data should give relevant insights for training, education and more work policies in general.

\section{ACKNOWLEDGEMENT}

Streblo is being developed within a European Commission (EC) project H2020-MSCA- IF2015/H2020-MSCA-IF-2015, Grant Agreement: 703236 - 'Inhibiting Stress in the Construction Industry' (INSTINCT). The authors are very grateful for this funding.

\section{REFERENCES}

Årsand, E, Muzny, M, Bradway, M, Muzik, J and Hartvigsen, G (2015) Performance of the first combined smartwatch and smartphone diabetes diary application study. Journal of Diabetes Science and Technology, 9(3), 556-563.

Bauer, U E, Briss, P A, Goodman, R A and Bowman, B A (2014) Prevention of chronic disease in the 21st century: Elimination of the leading preventable causes of premature death and disability in the USA. The Lancet, 384(9937), 45-52.

Benarie, M (1988) Delphi-and Delphilike approaches with special regard to environmental standard setting. Technological Forecasting and Social Change, 33(2), 149-158.

Bowen, P, Govender, R and Edwards, P (2014) Structural equation modelling of occupational stress in the construction industry. Journal of Construction Engineering and Management, 140(9), 1-14.

Bowen, P, Edwards, P, Lingard, H and Cattell, K (2014) Workplace stress, stress effects and coping mechanisms in the construction industry. Journal of Construction Engineering and Management, 140(3), 1-15.

Chan, I Y S, Leung, M Y and Liang, Q (2018) The roles of motivation and coping behaviours in managing stress: Qualitative interview study of Hong Kong expatriate construction professionals in mainland China. International Journal of Environmental Research and Public Health, 15(3), e561.

Chan, I, Leung, M Y and Yuan, T (2014) Structural relationships between cultural values and 
coping behaviours of professionals in the stressful construction industry. Engineering, Construction and Architectural Management, 21(2), 133-151.

Derr, J, Forst, L, Chen, H Y, and Conroy, L (2001) Fatal falls in the US construction industry, 1990 to 1999. Journal of Occupational and Environmental Medicine, 43(10), 853-860.

Engel, C C, Litz, B, Magruder, K M, Harper, E, Gore, K, Stein, N, and Coe, T R (2015) Delivery of self-training and education for stressful situations (DESTRESS-PC) A randomized trial of nurse assisted online self-management for PTSD in primary care. General Hospital Psychiatry, 37(4), 323-328.

Enshassi, A, Al-Swaity, E, Abdulaziz, R and Choudhry, R (2018) Coping behaviours to deal with stress and stressor consequences among construction professionals: A case study at the Gaza Strip, Palestine. Journal of Financial Management of Property and Construction, 23(1).

Gaggioli, A, Cipresso, P, Serino, S, Campanaro, D M, Pallavicini, F, Wiederhold, B K and Riva, G (2014) Positive technology: A free mobile platform for the self-management of psychological stress. Annual Review of Cybertherapy and Telemedicine, 199, 25-29.

Haydam, E and Smallwood, J (2016) Mental stress among civil engineering construction site agents and foremen in the Nelson Mandela May Metropole. Journal of Construction Project Management and Innovation, 6(1), 1375-1390.

Jonkman, N H, Westland, H, Groenwold, R. H, Ågren, S, Atienza, F, Blue, L, and Kempen, G I (2016) Do Self-Management Interventions Work in Patients With Heart Failure? Clinical Perspective: An Individual Patient Data Meta-Analysis. Circulation, 133(12), 1189-1198.

Khusid, M A and Vythilingam, M (2016) The emerging role of mindfulness meditation as effective self-management strategy, part 1: Clinical implications for depression, posttraumatic stress disorder and anxiety. Military Medicine, 181(9), 961-968.

Lazarus, R S (1966) Psychological Stress and the Coping Process. New York, US: McGrawHill. Leung, M Y, Chan, I Y S and Cooper, C L (2014) Stress Management in the Construction

Industry. Oxford, UK: John Wiley and Sons.

Leung, M Y, Chan, Y S and Olomolaiye, P (2008) Impact of stress on the performance of construction project managers. Journal of Construction Engineering and Management, 134(8), 644-652.

Leung, M Y, Liang, Q and Yu, J (2016) Development of a mindfulness-stress-performance model for construction workers. Construction Management and Economics, 34(2), 110-128.

Lorig, K R, Ritter, P, Stewart, A L, Sobel, D S, Brown Jr, B W, Bandura, A and Holman, H R (2001) Chronic disease self-management program: 2-year health status and health care utilization outcomes. Medical Care, 39(11), 1217-1223.

Mancini, M (2003) Time Management. New York: McGraw Hill.

Nevo, D and Chan, Y E (2007) A Delphi study of knowledge management systems: Scope and requirements. Information and Management, 44(6), 583-597.

Payne, H E, Lister, C, West, J H and Bernhardt, J M (2015) Behavioural functionality of mobile apps in health interventions: A systematic review of the literature. JMIR mHealth and uHealth, 3(1), e20.

Shaw, W S, Besen, E, Pransky, G, Boot, C R, Nicholas, M K, McLellan, R K and Tveito, T H (2014) Manage at work: A randomized, controlled trial of a self-management group intervention to overcome workplace challenges associated with chronic physical health 
conditions. BMC Public Health, 14(1), 515.

Sutherland, V and Davidson, M J (1993) Using a stress audit: The construction site manager experience in the UK. Work and Stress, 7(3), 273-286.

Wang, K C, Hsieh, Y H, Yen, C H, You, C W, Chen, Y C, Huang, M C and Chu, H H (2014) SoberDiary: A phone-based support system for assisting recovery from alcohol dependence. In: Proceedings of the 2014 ACM International Joint Conference on Pervasive and Ubiquitous Computing: Adjunct Publication, 13-17 September, Seattle, Washington, 311314.

Whitehead, L and Seaton, P (2016) The effectiveness of self-management mobile phone and tablet apps in long-term condition management: A systematic review. Journal of Medical Internet Research, 18(5), e97.

Wu, Y, Yao, X, Vespasiani, G, Nicolucci, A, Dong, Y, Kwong, J and Li, S (2017) mobile appbased interventions to support diabetes self-management: A systematic review of randomized controlled trials to identify functions associated with Glycemic efficacy. JMIR mHealth and uHealth, 5(3), e35. 